\title{
Assessment of the Knowledge and Practice of Fitness to Drive among Commercial Long Distance Drivers in Benin City
}

\author{
K. C. Okafor'1, E. C. Azuike², 0. H. Okojie ${ }^{3}$ \\ ${ }^{1}$ Department of Community Health, University of Benin Teaching Hospital, Benin, Nigeria \\ ${ }^{2}$ Department of Community Medicine, Chukwuemeka Odumegwu Ojukwu University/University \\ Teaching Hospital, Awka, Nigeria \\ ${ }^{3}$ Department of Community Health, University of Benin, Benin, Nigeria \\ Email:drokaforking sley@gmail.com
}

How to cite this paper: Okafor, K. C. Azuike, E. C., \& Okojie, O. H. (2018). Assessment of the Knowledge and Practice of Fitness to Drive among Commercial Long Distance Drivers in Benin City. Advances in Physical Education, 8, 205-223. https://doi.org/10.4236/ape.2018.82019

Received: July 13, 2017

Accepted: May 22, 2018

Published: May 25, 2018

Copyright (c) 2018 by authors and Scientific Research Publishing Inc. This work is licensed under the Creative Commons Attribution International License (CC BY 4.0).

http://creativecommons.org/licenses/by/4.0/

\begin{abstract}
Commercial long distance driving is progressively growing and accounts for significant part of the socio-economic life of the populace as individuals and families travel from one destination to another. Driver's role in road safety is attracting global attention as a component of the tripod system consisting of the road user, road environment and vehicle system. Unfortunately, most drivers are unaware of the need to have regular driver's fitness assessment. This study aimed at assessing the drivers' knowledge and practice of fitness to drive among commercial long distance drivers in Benin City, Edo State. A descriptive cross sectional study design was used, and data were collected from 315 commercial long distance drivers and their vehicles. Study was done from January to October, 2013. Respondents were recruited using systematic random sampling technique. Study instruments included structured interviewer administered questionnaires and focus group discussion guide. The results showed that $114(36.2 \%)$ were within the age group of $31-40$ years. Ninety-one $(28.9 \%)$ were in the 41 - 50 years age group and almost all the respondents $311(98.7 \%)$ were males while $4(1.3 \%)$ were surprisingly females. Of the 315 respondents, 177 (56.2\%) were aware of "medical examination for drivers". More than half (54.3\%) of commercial drivers had poor knowledge of fitness to drive. Over three quarters $(79.7 \%)$ had poor practice of fitness to drive. The respondents who were not seeing a doctor for treatment were less likely $(\mathrm{B}=-0.845)$ to have good knowledge of fitness to drive compared to those who were being treated by a doctor with odds of 0.446 . This was statistically significant $(\mathrm{p}=0.038)$. Of all the predictors of good practice of fitness to drive, good knowledge of fitness to drive and history of occurrence of RTA
\end{abstract}


were statistically significant predictors. Most commercial drivers had poor knowledge and practice of fitness to drive. It is recommended that health education and enlightenment should be done by transport park management. Fitness to drive should be enforced among drivers by road safety and drivers licensing agencies.

\section{Keywords}

Fitness to Drive, Medical Fitness, Knowledge, Practice

\section{Introduction}

Road deaths and injuries despite being largely preventable are massively wasteful, destroying lives beyond those of the actual victims, limiting future productivity and draining money from economies. The current deficit and losses from road traffic crashes, including spending on road traffic related events have reduced the funds available to national governments for other sectors like health service and education. Road mishaps are the single biggest non-natural killer of children and young people; thus there is a need to prioritize strategies and approaches to integrating road safety into public health, developing "place-based" approaches and accessing expertise and funding (WHO, 2009; OECD, 2008; ROSPA, 2012). Road safety can form a unique bond between the public, private and voluntary sectors in tackling one of the major social ills-preventable road deaths and injuries (OECD, 2008; ROSPA, 2012).

Assessing and monitoring of drivers fitness to drive is targeted at controlling the human component of the road safety system. Fitness to drive involves medical and non-medical evaluations of an individual's functions to ensure that they can drive safely. Medical conditions likely to affect driver's fitness include blackouts, cardiovascular disease, diabetes, musculoskeletal conditions, neurological conditions such as epilepsy, dementia and cognitive impairment due to other causes, psychiatric conditions, substance misuse/dependency, and sleep disorders, vision problems (Austroads, 2000; WHO, 2007; NHTSA, 2009; NTC, 2012). Also, fitness to drive assessment includes tests and examinations on visual assessment (visual acuity, visual field), hearing assessment, neurological (cerebrovascular accident), endocrine (diabetes mellitus), cardiovascular (hypertension), musculoskeletal (arthritis, muscle aches), alcohol \& drug habit, mental state and sleepiness scale assessment. After fitness assessment, a driver can be classified as fit to drive or unfit to drive. This assessment is done by a qualified medical practitioner (Austroads, 2000; NHTSA, 2009; NTC, 2012).

Human factors are responsible for $95 \%$ of accidents investigated (Treat, 1977; FRSC, 2008a, 2008b). These human factors include actions like inappropriate and excessive speed; presence of alcohol, medicinal or recreational drugs; fatigue and poor eyesight of road users. These human factors are related to the knowledge of drivers concerning their health status and road safety (Watkins, 2010). 
Drivers especially in developing countries may be unaware of the need for periodic fitness assessment while practice of medical fitness is commonly incidental (Oladehinde, Adeoye, \& Adegbehinde, 2007). Commercial drivers are not aware of the importance of fitness in relation to road safety. This is as a result of poor public enlightenment on the need for a fit driver and poor enforcement of the provisions of the high way code concerning visual screening before issuance of driver's license and absence of legislation on driver's fitness in Nigeria (Oladehinde, Adeoye, \& Adegbehinde, 2007; Adekoya, Owoeye, Adepoju, \& Ajaiyeoba, 2009). This lack of awareness will most likely translate to poor practice.

In Nigeria, visual screening and normal alcohol levels are mandatory for drivers licensing. Yet, majority (84\%) of commercial drivers had no visual examination done before issuance of a driver's license (Oladehinde, Adeoye, \& Adegbehinde, 2007). This raises questions on the level of implementation of road safety codes. About $15 \%$ of commercial bus drivers are unfit to drive this is because they were either unaware of it or had a wrong perception of what constitutes an adequate fitness for driving when using VA as a measure (Adekoya, Owoeye, Adepoju, \& Ajaiyeoba, 2009). Most (80.4\%) of them actually believed their vision was good enough to drive a commercial vehicle. This presents a great risk towards road traffic crashes occurrence in Nigeria (Oladehinde, Adeoye, \& Adegbehinde, 2007; Adekoya, Owoeye, Adepoju, \& Ajaiyeoba, 2009).

The objectives of this study were to assess the knowledge of FTD, the practice of FTD, and factors affecting knowledge and practice of FTD.

\section{Methodology}

A descriptive cross-sectional study was carried out between from to October, 2013 among 315 selected commercial long distance drivers in Benin City.

A systematic random sampling technique was used in selecting the respondents for this study.

Step 1: A list of registered parks was obtained from the Ministry of Transport, Edo state. All 17 registered parks with a total of 1022 drivers involved in long distance transportation were used for this study.

Step 2: Sampling interval calculation, $k=N / n$ :

Total No of commercial drivers in Benin City (N)/ Sample Size (n) = 1022/315 $=3$

Step 3: Sampling Frame; A sampling frame consisted of the nominal roll of all drivers (as presented by the management of each park) involved in long distance driving in each of the registered park involved in long distance travels in Benin City.

Step 4: The first unit (driver) was selected using simple random sampling between driver 1 and driver 3 on the sampling frame. Then, using the sampling interval (k) of 3 as calculated above, every third (kth) driver on the list of drivers was recruited from each transport company until the sample size of 305 was achieved. For example, if a driver with serial number 1 was selected using simple random sampling, the next driver was the driver with serial number $4(1+3=$ 
4), then 7 th, 10th, 13th, 16th, 19th, 22nd, 25th driver and so on.

Data collection tools were pre-tested among selected commercial long distance drivers operating in Auchi, Estako West Local Government Area of Edo State. The location is about $200 \mathrm{~km}$ from Benin City. Collected quantitative data was entered and analyzed using Statistical Package for Scientific Solution (SPSS) version 20. Descriptive and inferential analysis was carried out in line with the objectives of the study. The focus group discussion sessions was transcribed and typed. The content of the sessions were analysed using thematic analyses to identify recurrent themes. Systematic reading, coding and re-categorisation of the transcripts of focus group discussion sessions were carried out.

Quantitative variables that are normal in distribution such as age and weight were expressed as means \pm standard deviation. Qualitative data like gender, educational status, and marital status were presented as diagrams and percentages. Logistic regression was used to identify predictive variables for good knowledge, good practice of fitness to drive. Statistical test of association, were carried out using a 95 percent confidence interval.

Ethical approval was obtained from the ethical committee of the University of Benin Teaching Hospital. Permission was obtained from the community leader and youth leaders, while parents gave assent for questionnaires to be administered. Individual informed consent was attached to each questionnaire and the respondent gave his or her consent before the questionnaires were filled.

The assessment of fitness to drive was based on the spot examination of driver's health, and clinical judgment of the researcher, thus there was no room for repeated or further examination for confirmation of diagnosis. There could have been inter-observer error in taking measurements and clinical examinations done in this study.

\section{Results}

More than a third of the respondents 114 (36.2\%) were within the age group of 31 - 40 years. Ninety-one (28.9\%) were in the 41 - 50 years age group while 18 (5.7\%) fell within the 61 - 70 years age group. Most of the respondents 272 (86.3\%) were married, $28(8.9 \%)$ were single, 10 (3.2\%) were cohabiting, while 2 $(0.6 \%)$ were separated. Most of the married respondents 247 (90.8\%) were in monogamous marriages and $242(76.8 \%)$ had nuclear families. Almost all the respondents $311(98.7 \%)$ were males while $4(1.3 \%)$ were surprisingly females. More than half of the respondents 172 (54.6\%) had a secondary level of education, $112(35.6 \%)$ had a primary level of education while $12(3.8 \%)$ had no formal education. One hundred and sixty nine (53.3\%) respondents were Benin, 48 (15.1\%) were Esan, 21 (6.6\%) were Igbo, 19 (6.0\%) were Urhobo while smaller proportions were Etsako 15 (4.8\%), Yoruba 9 (2.9\%), Isoko 8 (2.5\%), Owan 7 (2.2\%) and Itsekiri 7 (2.2\%), Ukwuani 7 (2.2\%) and Ibibio 3 (1.0\%). Most of the respondents 300 (95.2\%) were Christians, 10 (3.2\%) were traditional in their beliefs while $5(1.6 \%)$ were Muslims. Two hundred and ninety three $(92.7 \%)$ of the 
respondents were resident in Edo state, 7 (2.3\%) were resident in Lagos, 7 (2.3\%) in Delta, while smaller proportions were resident in Oyo, Kwara and Rivers [(0.6\%) each] (Table 1$)$.

\subsection{Knowledge of Fitness to Drive}

More than half of the respondents 177 (56.2\%) were aware of 'medical examination for drivers' while 138 (43.8\%) were not. More than half of the respondents $92(52.0 \%)$ indicated that their work place was their source of information, 53 (29.9\%) indicated FRSC while 51 (28.8\%) indicated media as their source. All the respondents, who were aware of medical examination, agreed that it was important for driving. While One hundred and fifty one (85.3\%) stated that medical examination for drivers was important for safety on the road, 17 (9.6\%) stated that it was important because road safety officers says so. One hundred and sixty-four $(92.7 \%)$ of the respondents stated that services provided by fitness to drive assessment includes visual screening, 148 (83.8\%) mentioned cardiovascular examination, while respondents stated erroneously that counseling services 148 (83.8\%), health education 145 (82.5\%), immunization services 109 (62.0\%), HIV screening $112(63.7 \%)$ were services rendered at fitness to drive assessment. Majority of the respondents $138(78.0 \%)$ stated that doctors were responsible for fitness to drive assessment while $52(29.4 \%)$ stated nurses, 51 (28.8\%) stated road safety officer while 29 (16.4\%) stated Vehicle Inspection Officer (Table 2).

More than half 171 (54.3\%) and 123 (39.0\%) of commercial drivers had poor and good knowledge of fitness to drive respectively (Table 3 ).

\subsection{Practice of Fitness to Drive}

One hundred and fourteen (36.2\%) respondents had done medical examination for drivers while 201 (63.8\%) had not. Slightly more than half of the respondents 104 (51.7\%) who had not done medical examination for drivers stated that it was because they were not aware of it, $35(17.4 \%)$ stated that it was because they were occupied with other business matters, while $17(8.5 \%)$ stated that it was expensive, $21(10.4 \%)$ stated is was not necessary, $10(5.0 \%)$ said it was not available, 9 (4.5\%) claimed it was time consuming and $5(2.5 \%)$ stated it was due to their religion. More than a third of the respondents $45(39.5 \%)$ had done the medical examination 2 - 4 times in the last five years, 32 (28.1\%) had done it once, while $23(20.2 \%)$ had not done it at all in the last five years. Almost half of the respondents $54(47.4 \%)$ stated that their employers recommended their last fitness to drive assessment, 49 (43.0\%) stated that it was recommended by the road safety officer, 19 (16.7\%) stated VIO while $12(10.5 \%)$ stated doctor. More than half of the respondents $64(56.1 \%)$ stated that FTD was done for them before they started driving while 50 (43.9\%) stated that it was not done. A quarter, 16 (25.0\%) of the respondents who had done the FTD before they started driving stated that it was done for employment, $14(21.9 \%)$ claimed it was done for achieving their license and also $13(20.3 \%)$ said it was to test their fitness while 8 
Table 1. Socio-demographic characteristics of the respondents.

\begin{tabular}{|c|c|c|}
\hline Variable & Frequency $(n=315)$ & Percent \\
\hline \multicolumn{3}{|l|}{ Age (Years) } \\
\hline $21-30$ & 26 & 8.3 \\
\hline $31-40$ & 114 & 36.2 \\
\hline $41-50$ & 91 & 28.9 \\
\hline $51-60$ & 66 & 20.9 \\
\hline $61-70$ & 18 & 5.7 \\
\hline \multicolumn{3}{|l|}{ Marital status } \\
\hline Single & 28 & 8.9 \\
\hline Married & 272 & 86.3 \\
\hline Cohabiting & 10 & 3.2 \\
\hline Separated & 2 & 0.6 \\
\hline Divorced & 3 & 1.0 \\
\hline \multicolumn{3}{|l|}{ Marriage type $(\mathrm{n}=272)$} \\
\hline Monogamous & 247 & 90.8 \\
\hline Polygamous & 25 & 9.2 \\
\hline \multicolumn{3}{|l|}{ Family type } \\
\hline Nuclear & 242 & 76.8 \\
\hline Extended & 73 & 23.2 \\
\hline \multicolumn{3}{|l|}{ Sex } \\
\hline Male & 311 & 98.7 \\
\hline Female & 4 & 1.3 \\
\hline \multicolumn{3}{|l|}{ Level of education } \\
\hline No formal education & 12 & 3.8 \\
\hline Primary & 112 & 35.6 \\
\hline Secondary & 172 & 54.6 \\
\hline Tertiary & 19 & 6.0 \\
\hline \multicolumn{3}{|l|}{ Ethnic group } \\
\hline Benin & 169 & 53.7 \\
\hline Esan & 48 & 15.2 \\
\hline Igbo & 21 & 6.7 \\
\hline Urhobo & 19 & 6.0 \\
\hline Etsako & 15 & 4.8 \\
\hline Yoruba & 9 & 2.9 \\
\hline Isoko & 8 & 2.5 \\
\hline Owan & 7 & 2.2 \\
\hline Itsekiri & 7 & 2.2 \\
\hline Ukwuani & 7 & 2.2 \\
\hline Ibibio & 3 & 1.0 \\
\hline
\end{tabular}




\section{Continued}

\begin{tabular}{|c|c|c|}
\hline Religion & & \\
\hline Christianity & 300 & 95.2 \\
\hline African traditional religion & 10 & 3.2 \\
\hline Islam & 5 & 1.6 \\
\hline \multicolumn{3}{|l|}{ State of residence } \\
\hline Edo & 293 & 93.0 \\
\hline Lagos & 7 & 2.3 \\
\hline Delta & 7 & 2.3 \\
\hline Oyo & 2 & 0.6 \\
\hline Kwara & 2 & 0.6 \\
\hline Rivers & 2 & 0.6 \\
\hline Others $^{\mathrm{b}}$ & 2 & 0.6 \\
\hline \multicolumn{3}{|l|}{ Duration of driving (years) } \\
\hline $0-10$ & 84 & 26.7 \\
\hline $11-20$ & 113 & 35.9 \\
\hline $21-30$ & 63 & 20.0 \\
\hline $31-40$ & 49 & 15.6 \\
\hline $41-50$ & 6 & 1.8 \\
\hline
\end{tabular}

(12.5\%) gave no reason for doing it, $7(10.9 \%)$ said it was not necessary while 6 (9.4\%) said it was precautionary (Table 4 ).

Two hundred and fifty-one (79.7\%) respondents had poor practice of fitness to drive while $34(10.8 \%)$ had good practice (Table 5).

\subsection{Factors Affecting Knowledge and Practice of FTD}

Factors affecting knowledge

Good knowledge of fitness to drive increased with older age, as a higher proportion of those 50 years and older, 38 (45.2\%) had good knowledge of fitness to drive than those less than 50 years $85(36.8 \%)$, this finding was statistically significant $(\mathrm{p}=0.006)$. All female $4(100.0 \%)$ respondents had good knowledge of fitness to drive while 119 (38.3\%) males had good knowledge. This association was statistically significant $(p=0.035)$. Knowledge of FTD increased with increase in level of education, this finding was not statistically significant ( $\mathrm{p}=$ 0.484). More respondents involved in RTA 62 (41.1\%) had good knowledge of fitness to drive than those who had not had an RTA 61 (37.2\%). This was not statistically significant $(\mathrm{p}=0.563)$. More respondents $48(40.7 \%)$ who had been driving for more than 20 years had a good knowledge of FTD than of those who had been driving for 20 years and below 75 (38.1\%). Good knowledge increased with increase in duration of driving. This finding was however not statistically significant $(p=0.253)$. A higher percentage $49(49.5 \%)$ of those currently on doctors treatment had knowledge of fitness to drive, than those who were not 
Table 2. Respondents' knowledge of fitness to drive.

\begin{tabular}{|c|c|c|}
\hline Variable & Frequency & Percent \\
\hline \multicolumn{3}{|l|}{ Aware of medical examination for drivers $(n=315)$} \\
\hline Yes & 177 & 56.2 \\
\hline No & 138 & 43.8 \\
\hline \multicolumn{3}{|c|}{ Source of information on fitness to drive* $(n=177)$} \\
\hline Work place & 92 & 52.0 \\
\hline Federal Road Safety Commission (FRSC) & 53 & 29.9 \\
\hline Media & 51 & 28.8 \\
\hline Doctor & 30 & 16.9 \\
\hline Vehicle Inspection Officer (VIO) & 16 & 5.1 \\
\hline Others $^{\mathrm{a}}$ & 8 & 4.5 \\
\hline \multicolumn{3}{|l|}{ Importance of medical examination* $(n=177)$} \\
\hline For Road safety & 151 & 85.3 \\
\hline Compulsory at work & 46 & 26.0 \\
\hline Necessary for license & 36 & 20.3 \\
\hline Road Safety Officers say so & 17 & 9.6 \\
\hline Others ${ }^{\mathrm{b}}$ & 10 & 5.6 \\
\hline \multicolumn{3}{|l|}{ Services provided by FTD* $(n=177)$} \\
\hline Visual screening & 164 & 92.7 \\
\hline Counseling services & 148 & 83.8 \\
\hline Cardiovascular examination & 147 & 83.2 \\
\hline Health education & 145 & 82.1 \\
\hline Hearing examination & 140 & 79.3 \\
\hline Musculoskeletal examination & 131 & 74.3 \\
\hline Mental examination & 131 & 74.3 \\
\hline Alcohol and drug screening & 128 & 72.6 \\
\hline Treatment of diseases & 117 & 66.5 \\
\hline HIV screening & 112 & 63.7 \\
\hline Immunization & 109 & 62.0 \\
\hline \multicolumn{3}{|l|}{ Professional responsible for $\operatorname{FTD}^{*}(n=177)$} \\
\hline Doctor & 138 & 78.0 \\
\hline Nurse & 52 & 29.4 \\
\hline Road Safety Officer & 51 & 28.8 \\
\hline Vehicle Inspection Officer & 29 & 16.4 \\
\hline
\end{tabular}

Multiple response*.

seeing a doctor $74(34.3 \%)$. This finding was statistically significant $(\mathrm{p}=0.0007)$ (Table 6).

The predictors in the model were responsible for $25.4 \%$ to $35.4 \%$ of the variation observed in the outcome variable (good knowledge of fitness to drive). The only statistically significant predictor of the selected predictors of good 
Table 3. Respondents' level of knowledge of fitness to drive.

\begin{tabular}{ccc}
\hline Knowledge & Frequency $(\mathbf{n}=\mathbf{3 1 5})$ & Percent \\
\hline Poor knowledge & 171 & 54.3 \\
Fair knowledge & 21 & 6.7 \\
Good knowledge & 123 & 39.0 \\
Total & 315 & 100.0 \\
\hline
\end{tabular}

Table 4. Respondents practice of fitness to drive.

\begin{tabular}{|c|c|c|}
\hline Variable & Frequency & Percent \\
\hline \multicolumn{3}{|c|}{ Ever had medical examination for drivers done $(n=315)$} \\
\hline Yes & 114 & 36.2 \\
\hline No & 201 & 63.8 \\
\hline \multicolumn{3}{|c|}{ Number of times (in last 5 years) medical exam was done $(n=114)$} \\
\hline None & 23 & 20.2 \\
\hline Once & 32 & 28.0 \\
\hline $2-4$ times & 45 & 39.5 \\
\hline $5-7$ times & 10 & 8.8 \\
\hline $8-9$ times & 4 & 3.5 \\
\hline \multicolumn{3}{|c|}{ Reasons for not doing FTD $(n=201)$} \\
\hline Not aware of it & 104 & 51.7 \\
\hline Other job matters & 35 & 17.4 \\
\hline Not necessary & 21 & 10.4 \\
\hline Expensive & 17 & 8.5 \\
\hline Not available & 10 & 5.0 \\
\hline Time consuming & 9 & 4.5 \\
\hline Religious beliefs & 5 & 2.5 \\
\hline \multicolumn{3}{|c|}{ Person that recommended the last FTD ${ }^{*}(n=114)$} \\
\hline Employers & 54 & 47.4 \\
\hline Road safety officer & 49 & 43.0 \\
\hline Vehicle inspection officer & 19 & 16.7 \\
\hline Doctor & 12 & 10.5 \\
\hline Self & 7 & 6.1 \\
\hline Nurse & 2 & 1.8 \\
\hline Friends & 1 & 0.9 \\
\hline Others $^{* *}$ & 2 & 1.8 \\
\hline \multicolumn{3}{|c|}{ FTD done before driving $(n=114)$} \\
\hline Yes & 64 & 56.1 \\
\hline No & 50 & 43.9 \\
\hline \multicolumn{3}{|c|}{ Reason for doing FTD before driving $(\mathrm{n}=64)$} \\
\hline For employment & 16 & 25.0 \\
\hline For license & 14 & 21.9 \\
\hline For fitness & 13 & 20.3 \\
\hline No reason given & 8 & 12.5 \\
\hline Necessity & 7 & 10.9 \\
\hline Precautionary & 6 & 9.4 \\
\hline
\end{tabular}

Multiple response*. 
Table 5. Respondents' level of practice of fitness to drive.

\begin{tabular}{ccc}
\hline Practice & Frequency & Percent \\
\hline Poor practice & 251 & 79.7 \\
Fair practice & 30 & 9.5 \\
Good practice & 34 & 10.8 \\
Total & 315 & 100.0 \\
\hline
\end{tabular}

Table 6. Respondent's knowledge of fitness to drive and socio-demographic characteristics, currently on doctor's treatment.

\begin{tabular}{|c|c|c|c|c|c|c|c|}
\hline \multicolumn{8}{|c|}{ Knowledge of Fitness to drive $n=315$} \\
\hline \multicolumn{2}{|c|}{ Variables } & Poor $\mathrm{n}(\%)$ & Fair $\mathrm{n}(\%)$ & $\begin{array}{c}\text { Good n } \\
(\%)\end{array}$ & & $\begin{array}{c}\text { Test } \\
\text { statistic }\end{array}$ & $\mathrm{p}$ value \\
\hline \multirow{2}{*}{$\begin{array}{l}\text { Age group } \\
\text { (years) }\end{array}$} & $<50$ & $132(57.1)$ & $14(6.1)$ & $85(36.8)$ & & \multirow{2}{*}{$\begin{array}{c}\text { Fisher's } \\
\text { exact }=3.037\end{array}$} & \multirow{2}{*}{$0.006^{*}$} \\
\hline & $>50$ & $39(46.4)$ & $7(8.3)$ & $38(45.2)$ & & & \\
\hline \multirow{2}{*}{ Sex } & Male & $171(55.0)$ & $21(6.8)$ & $119(38.3)$ & & \multirow{2}{*}{$\begin{array}{c}\text { Fisher's } \\
\text { exact }=5.420\end{array}$} & \multirow{2}{*}{$0.035^{*}$} \\
\hline & Female & $0(0.0)$ & $0(0.0)$ & $4(100.0)$ & & & \\
\hline \multirow{4}{*}{$\begin{array}{l}\text { Level of } \\
\text { education }\end{array}$} & No formal & $8(66.7)$ & $0(0.0)$ & $4(33.3)$ & & \multirow{4}{*}{$\begin{array}{c}\text { Fisher's } \\
\text { exact }=5.136\end{array}$} & \multirow{4}{*}{0.484} \\
\hline & Primary & $66(58.9)$ & $8(7.1)$ & $38(33.9)$ & & & \\
\hline & Secondary & $89(51.7)$ & $13(7.6)$ & $70(40.7)$ & & & \\
\hline & Tertiary & $8(42.1)$ & $0(0.0)$ & $11(57.9)$ & & & \\
\hline \multirow{2}{*}{$\begin{array}{c}\text { Ever had an } \\
\text { RTA }\end{array}$} & Yes & $81(53.6)$ & $8(5.3)$ & $62(41.1)$ & & \multirow{2}{*}{$\chi^{2}=1.122$} & \multirow{2}{*}{0.563} \\
\hline & No & $90(54.9)$ & $13(7.9)$ & $61(37.2)$ & & & \\
\hline \multirow{3}{*}{$\begin{array}{c}\text { Duration of } \\
\text { driving } \\
\text { (years) }\end{array}$} & $\leq 20$ & $115(56.9)$ & $10(5.1)$ & $75(38.1)$ & & \multirow{2}{*}{$\begin{array}{c}\text { Fisher's } \\
\text { exact }=2.770\end{array}$} & \multirow{2}{*}{0.253} \\
\hline & $>20$ & $59(50.0)$ & $11(9.3)$ & $48(40.7)$ & & & \\
\hline & Yes & $48(48.5)$ & $2(2.0)$ & $49(49.5)$ & & \multirow{3}{*}{$\begin{array}{c}\text { Fisher's } \\
\text { exact }=9.759\end{array}$} & \multirow{3}{*}{$0.007^{\star}$} \\
\hline \multirow{2}{*}{$\begin{array}{l}\text { Currently on } \\
\text { doctors } \\
\text { treatment }\end{array}$} & No & $123(56.9)$ & $19(8.8)$ & $74(34.3)$ & & & \\
\hline & & & & 77 & $\begin{array}{c}216 \\
(100.0)\end{array}$ & & \\
\hline
\end{tabular}

*indicates statistical significance.

knowledge of fitness to drive was seeing a doctor for treatment. For a one year increase in the age of the respondents, the likelihood of having good knowledge of fitness to drive increases $(B=0.003$ ) by odds of 0.999 . This was not statistically significant $(\mathrm{p}=0.789)$. The respondents who were males were less likely $(\mathrm{B}=$ -21.073 ) to have good knowledge of fitness to drive compared to those who are females to have with odds of 0.00 . This was not statistically significant ( $\mathrm{p}=$ 0.999). The respondents who had had RTA were more likely $(B=0.143)$ to have good knowledge of fitness to drive compared to those who had never had an RTA by odds of 1.154 . This was not statistically significant $(p=0.547)$. The respondents who were not seeing a doctor for treatment were less likely $(\mathrm{B}=$ $-0.845)$ to have good knowledge of fitness to drive compared to those who were 
being treated by a doctor with odds of 0.446 . This was statistically significant ( $\mathrm{p}$ $=0.038)$ (Table 7).

More respondents 15 (16.5\%) aged 41 - 50 years had good practice of FTD than those less than 40 years 6 (5.3\%). Good practice of fitness to drive increased as age of the respondents increased, this finding was statistically significant ( $\mathrm{p}=$ 0.001). Respondents 4 (21.1\%) with tertiary level of education had good practice of FTD while $16(14.3 \%)$ of those with primary level of education had good practice. None of the respondents with no formal education had good practice. Good practice of fitness to drive increased as respondents level of education increased. This was statistically significant $(\mathrm{p}=0.006)$. A higher proportion of the married respondents $32(11.6 \%)$ had good practice of fitness to drive than those who were unmarried $2(4.6 \%)$. This association was statistically significant $(\mathrm{p}=$ 0.015). A higher percentage of respondents with more than 20 years driving experience $20(16.9 \%)$ had good practice of fitness to drive than those with 20 years or less driving experience $14(7.1 \%)$. There was a statistically significant difference in association between driving experience and practice of fitness to drive $(\mathrm{p}=0.018)$. A greater proportion of drivers with poor knowledge of FTD $152(88.9 \%)$ had poor practice of FTD, when compared with those with good knowledge 82 (66.7\%). Practice of FTD increased as knowledge of fitness to drive increased. The association between knowledge and practice of FTD was statistically significant $(p=0.001)$. A lower proportion of respondents who have been involved in RTA 10 (6.6\%) had good practice of FTD than those who had not been involved 24 (14.6\%). This finding was statistically significant $(\mathrm{p}=0.048)$ (Table 8).

The predictors in the model were responsible for $24.3 \%$ to $33.6 \%$ of the variation observed in the outcome variable (good practice of fitness to drive). Of all the predictors of good practice of fitness to drive, good knowledge of fitness to drive and history of occurrence of RTA were statistically significant predictors. For a one year increase in the age of the respondents, the likelihood of having good practice of fitness to drive increases $(B=0.028)$ by odds of 1.028 . This was not statistically significant $(\mathrm{p}=0.256)$. The respondents who were males were less likely $(\mathrm{B}=-1.113)$ to have good practice of fitness to drive compared to those who are female with odds of 0.328 . This was not statistically significant ( $\mathrm{p}$ $=0.338)$. The respondents who were unmarried were less likely $(B=-0.650)$ to have good practice of fitness to drive compared to those who were married by odds of 0.522 . This was not statistically significant $(\mathrm{p}=0.402)$. Respondents who have been driving for 20 years or less were less likely $(B=-0.508)$ to have good practice of fitness to drive compared to those with more than 20 years driving experience by odds of 0.601 . This was not statistically significant $(\mathrm{p}=0.323)$. The respondents who had poor knowledge of fitness to drive were less likely ( $\mathrm{B}=$ $-0.829)$ to have good practice of fitness to drive compared to those who had good knowledge by odds of 0.437 . This was statistically significant $(p=0.031)$. The respondents who were not seeing a doctor for treatment were less likely 
Table 7. Determinants of good knowledge of fitness to drive among the respondents (logistic regression).

\begin{tabular}{|c|c|c|c|c|c|}
\hline \multirow{2}{*}{ Predictors } & \multirow{2}{*}{$\begin{array}{l}\text { B (regression } \\
\text { coefficient) }\end{array}$} & \multirow{2}{*}{ p-value } & \multirow{2}{*}{ Odd Ratio } & \multicolumn{2}{|c|}{ 95\% C.I. for Odd ratio } \\
\hline & & & & Lower & Upper \\
\hline Age (years) & 0.003 & 0.789 & 0.999 & 0.974 & 1.020 \\
\hline \multicolumn{6}{|l|}{ Sex } \\
\hline Male & -21.073 & 0.999 & 0.000 & 0.000 & 0.000 \\
\hline Female & & & 1 & & \\
\hline \multicolumn{6}{|l|}{ Ever had RTA } \\
\hline Yes & 0.143 & 0.547 & 1.154 & 0.724 & 1.841 \\
\hline $\mathrm{No}^{* *}$ & & & 1 & & \\
\hline \multicolumn{6}{|c|}{ On Doctors Treatment } \\
\hline No & -0.845 & $0.038^{*}$ & 0.446 & 0.233 & 0.967 \\
\hline $\mathrm{Yes}^{* *}$ & & & 1 & & \\
\hline Constant & $1.18 \times 10^{10}$ & 0.999 & 20.806 & & \\
\hline
\end{tabular}

${ }^{* *}$ reference category, $\mathrm{R}^{2}=25.4 \%-35.4 \%$ C.I $=$ confidence interval.

Table 8. Respondents' practice of FTD and socio-demographic variable, knowledge of FTD and history of RTA.

\begin{tabular}{|c|c|c|c|c|c|c|}
\hline \multirow[b]{2}{*}{ Variables } & & \multirow[b]{2}{*}{ Poor n (\%) } & \multicolumn{4}{|c|}{ Practice Of Fitness to drive $n=315$} \\
\hline & & & Fair n (\%) & Good n (\%) & Test statistic & $\mathrm{p}$ value \\
\hline \multirow{5}{*}{ Age group } & $21-30$ & $20(76.9)$ & $6(23.1)$ & $0(0.0)$ & \multirow{5}{*}{$\begin{array}{c}\text { Fisher's } \\
\text { exact }=29.765\end{array}$} & \multirow{5}{*}{$0.001^{*}$} \\
\hline & $31-40$ & $96(83.3)$ & $13(11.4)$ & $6(5.3)$ & & \\
\hline & $41-50$ & $74(81.3)$ & $2(2.2)$ & $15(16.5)$ & & \\
\hline & $51-60$ & $52(78.8)$ & $4(6.1)$ & $10(15.2)$ & & \\
\hline & $61-70$ & $10(55.6)$ & $5(27.8)$ & $3(16.7)$ & & \\
\hline \multirow{2}{*}{ Sex } & Male & $249(80.1)$ & $30(9.6)$ & $32(10.3)$ & \multirow{2}{*}{$\begin{array}{c}\text { Fisher's } \\
\text { exact }=4.641\end{array}$} & \\
\hline & Female & $2(50.0)$ & $0(0.0)$ & $2(50 . .0)$ & & \\
\hline \multirow{3}{*}{$\begin{array}{c}\text { Knowledge of } \\
\text { FTD }\end{array}$} & Poor & $152(88.9)$ & $8(4.7)$ & $11(6.4)$ & \multirow{3}{*}{$\begin{array}{c}\text { Fisher's } \\
\text { exact }=22.530\end{array}$} & \multirow{3}{*}{$0.001^{*}$} \\
\hline & Fair & $17(81.0)$ & $1(4.8)$ & $3(14.3)$ & & \\
\hline & Good & $82(66.7)$ & $21(17.1)$ & $20(16.3)$ & & \\
\hline \multirow{4}{*}{$\begin{array}{c}\text { Level of } \\
\text { education }\end{array}$} & No formal & $7(58.3)$ & $5(41.7)$ & $0(0.0)$ & \multirow{4}{*}{$\begin{array}{c}\text { Fisher's } \\
\text { exact }=16.607\end{array}$} & \multirow{4}{*}{$0.006^{*}$} \\
\hline & Primary & $89(79.5)$ & $7(6.2)$ & $16(14.3)$ & & \\
\hline & Secondary & $140(81.4)$ & $18(10.5)$ & $14(8.1)$ & & \\
\hline & Tertiary & $15(78.9)$ & $0(0.0)$ & $4(21.1)$ & & \\
\hline \multirow{2}{*}{ Marital status } & Unmarried & $35(81.4)$ & $6(14.0)$ & $2(4.6)$ & \multirow{2}{*}{$\begin{array}{c}\text { Fisher's } \\
\text { exact }=16.920\end{array}$} & \multirow{2}{*}{$0.015^{*}$} \\
\hline & Married & $216(79.4)$ & $24(8.8)$ & $32(11.6)$ & & \\
\hline \multirow{2}{*}{$\begin{array}{c}\text { Duration of } \\
\text { driving (years) }\end{array}$} & $\leq 20$ & $161(81.9)$ & $22(11.2)$ & $14(7.1)$ & \multirow{2}{*}{$\chi^{2}=8.066$} & \multirow{2}{*}{$0.018^{*}$} \\
\hline & $>20$ & $90(76.3)$ & $8(6.8)$ & $20(16.9)$ & & \\
\hline \multirow{2}{*}{$\begin{array}{c}\text { Ever had an } \\
\text { RTA }\end{array}$} & Yes & $126(83.4)$ & $15(9.9)$ & $10(6.6)$ & \multirow{2}{*}{$\chi^{2}=5.262$} & \multirow{2}{*}{$0.048^{\star}$} \\
\hline & No & $125(76.2)$ & $15(9.1)$ & $24(14.6)$ & & \\
\hline
\end{tabular}

*indicates statistical significance. 
$(\mathrm{B}=-0.066)$ to have good practice of fitness to drive compared to those who were being treated by a doctor with odds of 0.068 . This was statistically significant $(\mathrm{p}=0.910)$. The respondents who had ever had RTA were more likely $(\mathrm{B}=$ $0.936)$ to have good practice of fitness to drive compared to those who had never had an RTA by odds of 2.549. This was statistically significant $(\mathrm{p}=0.022)$ (Table 9).

\subsection{Focus Group Discussions}

\section{KNOWLEDGE OF FITNESS TO DRIVE FOR DRIVERS}

Majority of drivers described fitness to drive as good health in driving, good rest for drivers, good eye sight, physical and mental balance, general physical condition, training on how to handle human lives in the vehicle, free from alcohol. One of the participants said:

"If you don't have any sickness, and no trouble then you are fit. Also, eye sight is there, this eye sight there are some people that cannot see far. As a driver you should be able to see things at a distance that means a driver should have good eye sight... I think as a driver you must be free from alcohol because you are carrying lives" ...A 36 year old driver with 7 years driving experience.

OPINION ON IMPORTANCE OF FITNESS TO DRIVE TO DRIVING

All commercial drivers agreed that fitness to drive was important to driving.

PRE-EMPLOYMENT FITNESS TO DRIVE ASSESSMENT

All respondents stated that they had no fitness to drive assessment done for them before their current employment. Most commercial long distance drivers informed that only road tests were carried out, some others verbal confirmation of driving experience was all that was requested.

\section{TYPES OF MEDICAL ASSESSMENT AND TEST DONE}

This domain addresses the different types of tests done by drivers on a personal basis within the year. Majority of the drivers stated that they had not had medical tests and assessment done for them personally. A few had done simple blood pressure checks, blood sugar level and eye test.

RESPONSIBILITY FOR REQUESTING FOR FITNESS TO DRIVE ASSESSMENT

Majority of the respondents agreed that management of the parks should be responsible for requesting and paying for a fitness to drive assessment for the drivers in their employment. Majority also claimed that management does not take responsibility for FTD. Few participants felt it was a personal decision to request for fitness to drive, while others felt the doctor should come to the parks to request for it.

\section{Discussion}

Commercial long distance drivers play a vital role in the socioeconomic life of most Nigerians, as people need to move from place to place, thus their health, fitness to drive as well as the state of their vehicles are of public health importance. 
Table 9. Determinants of good practice of fitness to drive among respondents.

\begin{tabular}{|c|c|c|c|c|c|}
\hline \multirow{2}{*}{ Predictors } & \multirow{2}{*}{$\begin{array}{l}\text { B (regression } \\
\text { coefficient) }\end{array}$} & \multirow{2}{*}{$\mathrm{p}$-value } & \multirow{2}{*}{ Odd Ratio } & \multicolumn{2}{|c|}{$95 \%$ C.I. for Odd ratio } \\
\hline & & & & Lower & Upper \\
\hline Age (years) & 0.028 & 0.256 & 1.028 & 0.980 & 1.079 \\
\hline \multicolumn{6}{|l|}{ Sex } \\
\hline Male & -1.113 & 0.338 & 0.328 & 0.034 & 3.209 \\
\hline Female $^{\star *}$ & & & 1 & & \\
\hline \multicolumn{6}{|l|}{ Marital Status } \\
\hline Unmarried & -0.650 & 0.402 & 0.522 & 0.143 & 5.686 \\
\hline Married $^{* *}$ & & & 1 & & \\
\hline \multicolumn{6}{|c|}{ Driving experience } \\
\hline$\leq 20$ years & -0.508 & 0.323 & 0.601 & 0.219 & 1.650 \\
\hline$>20$ years $^{\star *}$ & & & 1 & & \\
\hline \multicolumn{6}{|c|}{ Knowledge of FTD } \\
\hline Poor & -0.829 & $0.031^{\star}$ & 0.437 & 0.206 & 0.926 \\
\hline Good $^{* *}$ & & & 1 & & \\
\hline \multicolumn{6}{|c|}{ On Doctors treatment } \\
\hline No & -0.066 & 0.910 & 0.068 & 0.340 & 3.361 \\
\hline Yes ${ }^{* *}$ & & & 1 & & \\
\hline \multicolumn{6}{|l|}{ Ever had RTA } \\
\hline No & 0.936 & $0.022^{*}$ & 2.549 & 0.192 & 0.883 \\
\hline $\mathrm{Yes}^{\star *}$ & & & 1 & & \\
\hline Constant & -0.948 & 0.615 & 0.387 & & \\
\hline
\end{tabular}

${ }^{*}$ reference category, $\mathrm{R}^{2}=24.3 \%-33.6 \%$, Significant ${ }^{*}$, C.I $=$ confidence interval.

More than half of the respondents were aware of 'medical examination for drivers. This could be because of the on-going publicity and gradual incorporation of medical examination for drivers into the licensing process, where visual screening, alcohol and drug screening are requested for before issuance of driver's licenses. Most drivers indicated that their work place was their source of information. It is thus evident that more emphasis is being placed on the health and fitness of the drivers by the park management which on the long run would lead to a reduction in the frequency of road traffic accidents and improved safety on roads.

The Federal Road Safety Commission (FRSC) was the second highest source of information probably because of the current gradual incorporation of medical examination into the driver's license issuance process; this could also explain the higher proportion of respondents with awareness of medical fitness test, but, slightly more than half of respondents had poor knowledge of fitness to drive assessment. This level of knowledge among drivers presents a threat to imple- 
mentation of driver's fitness tests as drivers do not know about the fitness assessment thus will most likely not request for it. This may hinder their practice of fitness to drive. It is explainable that weak or a lack of enforcement of fitness to drive assessments promotes uncoordinated practice which largely characterizes the driver's fitness in developing countries like Nigeria. However, this observed poor knowledge and poor practice can be addressed by targeted programs like health education seminars and workshops for drivers to bridge this gap and improve driver's knowledge and practice. This also can be attributable to the fact revealed in the FGD that employers have not taken responsibility for fitness to drive as an occupational health service that will be of benefit to the transport firms in terms of driver's motivation and output.

Majority of respondents knew the services offered by an ideal fitness to drive assessment to include; visual screening, cardiovascular, musculoskeletal, mental examination and alcohol screening. A plausible explanation for this finding is the fact that this study showed that more than half of the drivers were aware of driver's fitness while just below half had fair or good knowledge of fitness to drive. This knowledge of services that make up fitness to drive, personnel responsible for the fitness to drive and conditions that can affect driving could enable the drivers make specific demands on medical assessments they require and choice of expertise to keep them fit to work. Most commercial drivers also knew seizures and fits, fainting, bad brakes, bad and slippery roads, bad tyres were conditions to watch out for in order to avoid road traffic accidents. Studies done in New South Wales Australia revealed similar findings where $70 \%$ of the drivers knew medical conditions that affected driving, driving assessment needed and who was responsible for the assessments (Anstey, 2006). In contrast, a study done in Dar es Salaam Tanzania showed that $49.5 \%$ of the drivers had poor knowledge of fitness to drive (Kagashe \& Seleman, 2009).

Interestingly, just over a third of the respondents had done medical examination for drivers. Of this, more than a third practiced it regularly (2 - 4 times in the last 5 years). Just over a tenth had good practice of fitness to drive, this relatively suboptimal percentage is consistent with findings from studies done in Brisbane, Australia, Haifa and Ashod, Israel, Ile Ife where proportion of drivers who practiced fitness to drive were $10 \%, 17.5 \%$ and $16.4 \%$ respectively (McConnell, Spall, \& Hirst, 1991; Friedman \& Richter, 2005; Oladehinde, Adeoye, \& Adegbehinde, 2007). Quite distinctly, studies done in Brisbane, Australia and Perak and Selangor, Malaysia revealed much higher proportions of $85 \%, 76 \%$ respectively (Anstey, 2006; Foon, Chan, \& Fah, 2009). This could be because more than half of the respondents who had not done medical examination for drivers stated they were not aware of it, others stated that they had other matters; some said it was not necessary, some claimed it was not available and others that it was expensive. Also, the studies that showed that majority had good practice were done among older drivers who would most likely visit their doctor more often. 
Greater proportions of respondents had their last fitness to drive examination recommended by their employers and road safety officer. This implies that employers and road safety officers have essential roles to play in fitness to drive implementation and enforcement. This observation raises concern for the employers to take responsibility for organizing drivers fitness assessments as delineated by Thomas Legge in his aphorism which states: "Unless and until the employer has done everything-and everything means a good deal-the workman can do next to nothing to protect himself, although he is naturally willing enough to do his share" (Asogwa, 2007).

More than half of the respondents claimed that FTD was done for them before they started driving, most were for employment and getting a license. Lower proportions were observed in Ile Ife and Haifa, Israel (Friedman \& Richter, 2005; Oladehinde, Adeoye, \& Adegbehinde, 2007). This is not surprising since there is no legislation or enforcement of fitness examinations before employment, as focal group discussion revealed that employers only informed drivers of the need to check their health but were unwilling to pay for medical examinations.

The finding that good knowledge of fitness to drive increased with increase in age shows that much older drivers have sufficient information on fitness to drive, probably due to longer working experience. This trend probably affected their practice as good practice of fitness to drive also increased with increasing age. It is thus rational to posit that the effect of this was that more respondents older than 50 years will be more careful about their health and fitness than those younger than 50 years. By implication, older drivers present a risk to road safety as most disease conditions that will affect driving present as drivers get older, thus they should be targeted for enlightenment on the importance of drivers fitness in road safety.

Of note is the fact that all the female respondents had good knowledge while over a third of the males had good knowledge. This may be attributable to the fact that since the profession is male dominated, female drivers would be eager to seek expertise and skill on the requirements for healthy driving and road safety. Furthermore, studies have shown that females are more concerned about their health than their male counterparts (Stock, Willie, \& Kramer, 2001; Suraj \& Singh, 2011). However, this was statistically significant implying that knowledge of fitness to drive may be dependent on gender. Interestingly, this apparently good knowledge demonstrated by women in commercial driving also impacted on their practice as half of the female respondents had good practice of fitness to drive.

It is worthy of note that, knowledge of FTD increased with increase in level of education, this is not unexpected as education generally enhances knowledge and broaden the mindset of drivers. Furthermore, education improves driver's ability to recognize and report conditions that will impair their driving ability and seek medical care appropriately. There was a statistically significant association between good practice of fitness to drive and driver's level of education as good practice of fitness to drive increased as respondent's level of education in- 
creased. Furthermore, more respondents without formal education were unfit to drive than those with formal education. Driver's fitness to drive increased with increase in level of education. Formal education creates an opportunity for learning, skill acquisition and development of habits for living. Thus, it is expected that education and driver enlightenment will help sustain and improve their knowledge and practice.

The observation that good knowledge increased with increase in duration of driving, could be attributable to years of experience of the drivers. Some have worked for different transport firms who may have demanded a medical examination as revealed by the focal group discussion. Their years of experience may also have enabled them witness health and fitness campaigns, seminars and talks. These drivers can serve as peer educators for their colleagues. They can also facilitate and encourage other drivers to go for regular driver's fitness assessment. It is expected that the senior and more experienced drivers would command respect among their peers. Correspondingly, good practice of driver's fitness increased with increasing driver's experience. This finding was statistically significant. Moreover, more drivers with more than 20 years driving experience were fit to drive than those with 20 years or less than driving experience. Fitness to drive increased with increase in duration of driving. This finding was not statistically significant, but reflects the crucial role which drivers experience plays in road safety.

It was however unexpected that higher proportion of those involved in RTA had good knowledge of FTD than those who had not had an RTA. This was not statistically significant, but it suggests that involvement in an RTA may have improved their knowledge by virtue of sheer experience and exposure to medical personnel who attended to them when they had the RTA. Those involved in previous accidents may seek ways of avoiding re-occurrence of the RTA. Distinctly, there was a statistically significant association between involvement in road traffic accidents and good practice of fitness to drive, as a higher proportion of respondents who have been involved in RTA had good practice of FTD than those who had not been involved Also, on logistic regression, having had an RTA and good knowledge of FTD are predictors of good practice of FTD. However, it is not recommended that drivers wait until road traffic accidents occur before seeking regular medical fitness tests because RTAs commonly result in loss of life and severe injuries which may prevent the driver from continuing with the occupation.

\section{Conclusion and Recommendation}

The study showed that commercial long distance drivers in Benin City, Edo State had poor knowledge and practice of fitness to drive.

\section{Commercial Long Distance Drivers and Drivers Union}

1) Commercial drivers should improve their practice of fitness to drive by ensuring periodic medical assessment in accredited hospitals in order to remain healthy enough to stay on the wheels. 
2) Drivers Union should have peer group cooperation, discussions and advocacy on how best to ensure all members have regular health checks.

\section{Transport Companies and Parks}

1) Ensure that all drivers have fitness to drive assessment before employment, conduct periodic medical examination and other forms of health assessment to monitor driver's health.

2) Transport companies should provide fitness to drive assessments as part of occupational health services (OHS) available to all workers in their employ. And ensure adequate driver training on good posture while driving and other ergonomic problems of long distance driving like neck pain, back pain and fatigue.

3) Services rendered by fitness to drive assessment should be made available at reduced cost or no cost to the drivers to improve accessibility.

4) Conduct advocacy to government on need to adopt health insurance schemes for drivers to aid practice of fitness to drive.

\section{Road Safety Officers and Drivers and Vehicle Licensing Authority}

1) Enforcement of fitness to drive assessment should be done especially before issuance of driver's license.

2) Ensure prosecution and penalty (fines) for transport operators that employ drivers who have been declared unfit to drive.

\section{Government}

1) State governments should subsidize the cost of health services used for medical examinations, especially fitness to drive using National Health Insurance Scheme (NHIS).

2) Support and initiate policies and evidence based research that could serve as standard national guideline on fitness to drive.

3) Legislation and enactment of laws back up the enforcement of fitness to drive for drivers.

4) Extend health insurance to private sector to help reduce the out-of-pocket spending on health care to reduce cost of fitness to drive.

\section{References}

Adekoya, B. J., Owoeye, J. F., Adepoju, F. G., \& Ajaiyeoba, I. (2009). Visual Function Survey of Commercial Intercity Vehicle Drivers in Ilorin, Nigeria. Canadian Journal of Ophthalmology/Journal canadien d'ophtalmologie, 44, 261-264. https://doi.org/10.3129/i09-049

Anstey, A. K. J. (2006). Health Knowledge Related to Driving, and Driving Associated Anxiety: A Public Health Approach to Driving in Later Life (pp. 45-56). Canberra: Australian National University.

Asogwa, S. E. (2007). Guide to Occupational Health Practice in Developing Countries (4th ed., p. 3). Enugu: Fourth Dimension Publishers.

Austroads (2000). The Austroads Report on Drugs and Driving in Australia. Sydney: Austroad Publishers.

Federal Road Safety Commission FRSC (2008a). Federal road Safety Annual Report (pp. 3-5). Abuja: FRSC.

Federal Road Safety Commission FRSC (2008b). Nigeria Highway Code (pp. 26-28). Ab- 
uja: FRSC.

Foon, Y. S., Chan, B., \& Fah, Y. (2009). Driving Practices of Older Malaysian Drivers: The Influence of Knowledge, Attitude and Confidence. European Journal of Social Sciences, 12, 65-75.

Friedman, L., \& Richter, E. D. (2005). Working Conditions and Fatigue in Professional Truck Drivers at Israeli Ports. Injury Prevention, 11, 110-114. https://doi.org/10.1136/ip.2004.007682

Kagashe, G. A. B., \& Seleman, K. (2009). Knowledge, Attitude and Practice of Commercial Drivers in Dar es Salaam with Regard to Medicines That Impair Driving. Tropical Journal of Pharmaceutical Research, 8, 297-302. https://doi.org/10.4314/tjpr.v8i4.45220

McConnell, R. A., Spall, A. D., \& Hirst, W. G. (1991). A Survey of the Visual Acuity of Brisbane Drivers. Brisbane, Austalia. The Medical Journal of Australia, 155, 107-111.

National Highway Traffic Safety Administration NHTSA (2009). Driver Fitness Medical Guidelines. Washington DC: NHTSA.

National Transport Commission NTC (2012). Assessing Fitness to Drive for Commercial and Private Vehicle Drivers (pp. 16-60). Sydney: Austroads Publication.

http://www.austroads.com.au

Oladehinde, K., Adeoye, A. O., \& Adegbehinde, B. O. (2007). Visual Functions of Commercial Drivers in Relation to Road Accidents in Nigeria. Indian Journal of Occupational and Environmental Medicine, 11, 71-75.

https://doi.org/10.4103/0019-5278.34532

Organisation for Economic Cooperation \& Development OECD (2008). Towards Zero: Ambitious Road Safety Targets and the Safe System Approach (pp. 29-34). Paris: OECD Publishing. http://www.internationaltransportforum.org

Royal Society for the Prevention of Accidents ROSPA (2012). Making It Count (pp. 2-5). UK: ROSPA. http://www.rospa.com/

Stock, C., Willie, L., \& Kramer, A. (2001). Gender Specific Health Related Behaviours of German University Students Predicting the Intervention of Campus Health Promotion. Health Promotion International, 16, 145-154. https://doi.org/10.1093/heapro/16.2.145

Suraj, S., \& Singh, A. (2011). Study of Sense of Coherence Health Promoting Behaviour in North Indian Students. Indian Journal of Medical Research, 134, 645-652. https://doi.org/10.4103/0971-5916.90989

Treat, J. R. (1977). Tri-Level Study of the Causes of Traffic Accidents: An Overview of Final Results. In American Association for Automotive Medicine Conference (p. 402).

Watkins, K. (2010). The Missing Link: Road Traffic Injuries and the Millennium Development Goals (pp. 23-30). UNESCO. http://www.makeroadssafe.org

World Health Organization WHO (2007). Drug Abuse, Alcohol and Injury. Geneva: World Health Organization, Department of Injuries and Violence Prevention.

World Health Organization WHO (2009). Global Status Report on Road Safety: A Time for Action (p. 22). Geneva: World Health Organization Department of Violence \& Injury Prevention \& Disability (VIP).

http://www.who.int/violence_injury_prevention/road_safety_status/2009 